\title{
Embodied relations are encoded in language
}

\author{
MAX M. LOUWERSE \\ University of Memphis, Memphis, Tennessee
}

\begin{abstract}
Studies of embodied cognition have shown that comprehenders process iconic word pairs (attic-basement) more quickly than reverse-iconic pairs (basement-attic) when the pairs are presented to them in a vertical spatial arrangement. This effect disappears in a horizontal spatial arrangement. This has been claimed to show that comprehenders perceptually simulate these word pairs. A complementary explanation is that linguistic conceptualizations (word order) reflect prelinguistic conceptualizations (spatial iconicity), whereby comprehenders use these linguistic conceptualizations in the comprehension process. The results of corpus linguistic, rating, and semantic judgment studies reported here supported this explanation: Iconic word pairs were more frequent than reverse-iconic word pairs; frequency of word order explained response times in a semantic judgment task better than iconicity did; and when iconic word pairs were presented in a horizontal arrangement, the iconicity effect disappeared, but the word order effect remained. These findings show that spatial iconicity patterns are reflected in word order patterns and that comprehenders are sensitive to these word order patterns in language-processing tasks.
\end{abstract}

Recent theories of embodied cognition argue that the meaning of linguistic symbols can be captured only by grounding them in the human body and its interaction with the environment (Pecher \& Zwaan, 2005). These theories of cognition respond to theories of representation that argue that the meaning of linguistic symbols can be captured by their relation to other linguistic symbols (Landauer, McNamara, Dennis, \& Kintsch, 2007). For instance, according to the embodied account, the binomial attic and basement is understood by grounding the words in comprehenders' experiences with ascending stairs to attics and descending stairs to basements. According to the symbolic account, attics and basements are understood by the fact that both are nouns and have relations to semantic neighbors such as upstairs, downstairs, house, and room.

Various embodied cognition studies suggest that language comprehension is based on physical interactions and perceptual experiences comprehenders have with their environment. For instance, Kaden, Wapner, and Werner (1955) found an interplay between semantic aspects of words and perceptual processes when participants compared upward motion words (e.g., rising, climbing) and downward motion words (e.g., dropping, plunging). Spivey and Geng (2001) found that participants' eye movements acted out the mental image of a passage they read. Šetić and Domijan (2007) found, in a semantic judgment experiment, that words for flying animals were responded to more quickly in the upper part of a visual display, whereas for nonflying animals, the opposite was true. Finally, in a semantic judgment task, Zwaan and Yaxley (2003) presented participants with word pairs either in their iconic order (the word attic being presented above the word basement) or in the reverseiconic order (basement above attic). Response times (RTs) were longer in the reverse-iconic condition than in the iconic condition, presumably due to activation of perceptual simulations. Presentations matching perceptual representations facilitated processing. Further evidence for these perceptual simulations in word processing has come from an experiment in which the same items presented horizontally did not reveal any differences. Zwaan and Yaxley thus concluded, "we were able to rule out that this effect was due to the order in which the words were read" (p. 957).

Language comprehension has frequently been portrayed as either symbolic or embodied (see Louwerse \& Jeuniaux, 2008, for an overview). It may be true that without reference to the outside world, linguistic symbols are meaningless (Pecher \& Zwaan, 2005), but at the same time, much information about the world can be learned through exposure to these linguistic symbols (Landauer et al., 2007). Instead of viewing language comprehension as either symbolic or embodied, there is a third possibility that language is organized so that it reflects embodied relations (Louwerse, 2007; Louwerse, Cai, Hu, Ventura, \& Jeuniaux, 2006). That is, prelinguistic conceptual knowledge (spatial iconicity) used when speakers formulate utterances gets translated into linguistic conceptualizations (word order patterns; Levelt, 1989), so that as a function of language use, embodied relations are encoded in language. Indeed, embodiment studies have shown a recognition of the importance of embodied cognition, but the question that remains to be answered is whether and, if so, how linguistic structures use embodiment relationships (Bergen, Lindsay, Matlock, \& Narayanan, 2007). The present research addresses this question.

If language encodes embodied relations, this would imply that in the comprehension process, comprehenders can ben-

M. M. Louwerse, mlouwerse@memphis.edu 
efit from interrelations between symbols because these are mapped onto relations in the real world. To illustrate this, take the following example. Latin has a flexible word order. At the same time, Caesar's veni, vidi, vici is quite a different victory than vidi, vici, veni, as the language joke goes. Similarly, it is not a coincidence that low and high is less common than high and low, because the structure of the world is coded in language (Cooper \& Ross, 1975). Of course, the argument can be made that word order such as that found in such frozen binomials as up and down, top and bottom, and above and below is based on societal conventions, but one could also argue that these patterns demonstrate that there is a systematic relationship between the ordering of the words and what those words refer to. As Benor and Levy (2006) put it, "Since a speaker has eyes in her head not in her feet, looks forward rather than backward, and stands upright, elements that are front, above, and vertical are less marked [i.e., convey the default meaning]" (p. 238) and are more likely to precede their counterparts (see also Cooper \& Ross, 1975; Givón, 1989).

The present research tested whether linguistic conceptualizations (word order) reflect prelinguistic conceptualizations (spatial iconicity) and whether comprehenders use these linguistic conceptualizations in the comprehension process. For this purpose, we used Zwaan and Yaxley's (2003) iconicity study, described earlier, which concluded that online perceptual simulations must have taken place in the faster processing of iconic word pairs of the type attic-basement, placed in a vertical arrangement, than of reverse-iconically presented word pairs such as basementattic placed in a vertical arrangement. However, an alternative explanation for Zwaan and Yaxley's findings is that iconic word pairs appear more frequently in language than do their reverse-iconic counterparts, making frequency of word order an important factor in language comprehension, an effect ruled out by the authors (p. 957).

The claim that language encodes embodied relations leads to the following predictions: (1) Iconic word pairs (attic-basement) are more frequently found in language than are reverse-iconic word pairs (basement-attic); (2) frequency of word pairs explains RTs in a vertical arrangement (iconic vs. reverse-iconic) of word pairs at least as well as embodied relations do; and (3) frequency of word pairs explains RTs better than do embodied relations in a horizontal (i.e., noniconic) spatial arrangement. The first hypothesis was tested in a corpus linguistic study; the second and third hypotheses were tested in two semantic judgment experiments with both a vertical spatial arrangement and a horizontal spatial arrangement of word pairs. The results of these studies show that spatial iconicity patterns are reflected in word order patterns and that comprehenders are sensitive to these word order patterns in language-processing tasks.

\section{STUDY 1}

\section{Method}

All 71 word pairs used in Zwaan and Yaxley's (2003) experiments were selected for a frequency analysis in which raw and relative frequencies were identified for three to five word grams (Appendix A).
That is, the frequency of attic-basement and basement-attic was obtained when one to three words occurred between the target words. Frequencies were obtained from the large Web $1 T$ 5-gram corpus (Brants \& Franz, 2006), consisting of 1 trillion words (13,588,391 types) from 95,119,665,584 sentences.

\section{Results and Discussion}

In order to determine whether frequencies for iconic word pairs were different from those for reverse-iconic word pairs a chi-square with Yates's correction factor was used, with the significance level set at $1 \%$. Of the 71 word pairs, $57.75 \%$ had a higher frequency for the iconic word pairs than for the reverse-iconic word pairs. A total of $32.39 \%$ of the word pairs were more frequent in their reverse-iconic order than in their iconic order. Of the remaining $9.97 \%$ ( 7 word pairs), 4 did not yield significantly different frequencies, and the other 3 had zero frequencies. The zero-frequency pairs, which included handrail-porch, icing-doughnut, stoplight-street, can be explained by the absence of the words handrail, doughnut, and stoplight in the corpus.

Overall, the frequencies of the iconic word pairs were significantly different from those of the reverse-iconic word pairs $(z=-2.33, p=.02$; median $=2,276$ vs. 1,744). A maximum likelihood estimation (MLE) taking into account not only the word pair frequencies, but also the frequency of the first word in the word pair showed the same difference between iconic and reverse-iconic word pair frequencies $(z=-2.47, p=.01)$.

A total of 23 word pairs had higher frequencies for their reverse-iconic order than for their iconic order. These word pairs and their frequencies are presented in Table 1. The reason that these 23 word pairs had a frequency contrary to the iconicity pattern needs further investigation. How-

Table 1

Twenty-Three Word Pairs With Frequency-of-Word-Order Patterns Opposite the Patterns Predicted by the Iconicity Account

\begin{tabular}{|c|c|c|c|}
\hline Word1 & Word2 & [Word1 - Word2] & [Word $2-$ Word 1$]$ \\
\hline antenna & radio* & 9,163 & 15,057 \\
\hline antler & deer* & 833 & 1,676 \\
\hline boot & heel $^{\dagger}$ & 6,530 & 12,898 \\
\hline branch & root & 3,209 & 25,701 \\
\hline ceiling & floor & 46,118 & 169,711 \\
\hline curtain & stage* $^{*}$ & 1,172 & 1,698 \\
\hline fender & tire & 271 & 590 \\
\hline flower & stem $^{\dagger}$ & 3,872 & 5,099 \\
\hline fountain & pool $^{*}$ & 3,704 & 7,101 \\
\hline froth & coffee* & 146 & 398 \\
\hline grill & charcoal $^{\dagger}$ & 2,410 & 6,088 \\
\hline handle & bucket* & 605 & 1,281 \\
\hline headlight & bumper & 128 & 219 \\
\hline jam & toast* & 1,808 & 5,936 \\
\hline jockey & horse & 2,070 & 3,542 \\
\hline lid & box $^{*}$ & 16,918 & 28,231 \\
\hline lid & cup* & 1,852 & 5,789 \\
\hline lighthouse & beach* & 363 & 2,080 \\
\hline mantle & fireplace* & 8,785 & 10,404 \\
\hline mustache & beard* & 3,937 & 13,199 \\
\hline pedestrian & sidewalk & 914 & 1,265 \\
\hline penthouse & lobby & 1 & 58 \\
\hline sweater & pants & 2,156 & 2,529 \\
\hline
\end{tabular}

*Meronymy relation. †Holonymy relation. 
ever, of the 22 holonymy (bucket-handle) and meronymy (handle-bucket) relations that can be identified in the 71 Zwaan and Yaxley (2003) word pairs, 15 are found in the word pairs listed in Table 1. Moreover, of these 15 word pairs, 11 follow the pattern of whole-part (e.g., box-lid), which Cooper and Ross (1975) have identified to be more frequent than their part-whole counterpart (e.g., lid-box). The explanation here is that we perceive whole objects before we perceive their parts and language. Again, this prelinguistic conceptualization may have driven the linguistic conceptualization, as reflected in word order, with holonymy being more prevalent in word pair frequency than is iconicity.

In Zwaan and Yaxley's (2003) study, iconicity was treated as a categorical variable (word pairs were either iconic or reverse-iconic). However, a ratio scale of measurement could also be used. In the present study, knowing the magnitude of iconicity has the additional advantage that two ratio scale variables (i.e., iconicity and frequency) can be compared.

\section{STUDY 2}

In the second study, participants were asked to rate the likelihood that one concept appeared above the other. If language encodes embodied relations, the prediction would be that those word pairs that are considered to be more iconic have a higher word order frequency.

\section{Method}

Participants. Twenty-eight participants, all undergraduate students in psychology at the University of Memphis, participated in this study for course credit.

Procedure. The participants were asked to rate to what extent the 71 word pairs represented an iconic relationship by estimating the likelihood that one concept appeared above the other in the real world. Word pairs were presented in a vertical arrangement on paper, and ratings were made on a scale of $1-6$, with 1 being extremely unlikely and 6 being extremely likely. The ratings were obtained only for word pairs in their iconic order (attic-basement), since rating iconicity for reverse-iconic pairs (basement-attic) was considered awkward.

\section{Results}

Interrater reliability (Cronbach's $\alpha=.86$ ) was good to excellent (Nunnally \& Bernstein, 1994). The average participant rating of all the word pairs was $4.63(S D=0.25)$.

As was predicted, the average participants' ratings correlated significantly with the word pair frequencies from Study $1(r=.31, p<.001, N=71)$. Moreover, ratings were compared for the word pairs in Study 1 that had frequencies following iconicity order and those that did not (Table 1). Word pairs with frequency patterns matching the iconicity pattern received significantly higher ratings than did word pairs that did not match the iconicity pattern $[M=4.68, S D=0.72$ vs. $M=4.54, S D=0.75 ; t(27)=$ $2.67, p=.018]$.

The results of this and the previous analysis provided evidence for the hypothesis that word order correlates with spatial iconicity. In Study 1, we found that iconic word pairs have a higher frequency than do reverse-iconic word pairs. Study 2 showed that within the iconic word pairs, those with a higher frequency tend to have higher iconicity ratings.

However, these corpus linguistic findings do not prove that word order has an effect on cognitive processing. To test this prediction, a replication of Zwaan and Yaxley (2003) is needed, showing that word order can explain the variance in RTs at least as well as the iconicity relation between the two words can. This was done in Experiment 1.

\section{EXPERIMENT 1}

Experiment 1 used the stimuli from Zwaan and Yaxley (2003) to test spatial iconicity and word order effects. To ensure that word order effects were not limited to these iconic word pairs, items from Benor and Levy (2006) were included that did not have an obvious iconicity relation.

\section{Method}

Participants. Thirty-two undergraduate students from the University of Memphis participated in this experiment for course credit.

Materials and Procedure. Each participant saw 86 word pairs from Zwaan and Yaxley (2003) and Benor and Levy (2006), whereby one word appeared above the other. The presentation of each word (one above the other) was fully counterbalanced (see Appendixes A and B). All 26 word pairs used in Zwaan and Yaxley's Experiments 1 and 2 were used, as well as 60 of the 346 items from Benor and Levy, by taking 30 word pairs with the highest and 30 with the lowest semantic associations, as determined by latent semantic analysis (LSA; Landauer \& Dumais, 1997).

The participants were seated in front of a 17 -in. computer screen. The experiment was run on PCs using E-Prime software. The participants received instructions to judge the semantic relatedness of word pairs presented to them. The words were presented in black Courier font, font size 18, on a white background and subtended, at most, $1.35^{\circ}$ of vertical visual angle from a distance of $48 \mathrm{~cm}$. First, the participants were presented with an asterisk (*) at the center of the screen, followed by a word pair after $1 \mathrm{sec}$. The participants rated, as soon as possible, whether the items were semantically similar or not. Half of the participants pressed the " $x$ " key for similar items and the "." key for dissimilar items, whereas for the other half, the assignment of these keys were reversed. After five practice items, the participants were given the opportunity to ask questions, followed by the start of the experiment.

\section{Results and Discussion}

RTs at or below $550 \mathrm{msec}$ or longer than $3 \mathrm{SDs}$ from each participant's condition mean, were considered outliers and were removed from the analysis. This affected $2.7 \%$ of the data.

RTs for iconic items [attic-basement] were shorter $(M=1,230.54, S D=202.99)$ than those for the reverseiconic items [basement-attic] $(M=1,281, S D=215.04)$. This difference was significant $\left[F_{1}(1,31)=5.27, M S_{\mathrm{e}}=\right.$ $7,856.28, p=.029, \eta_{\mathrm{p}}^{2}=.15 ; F_{2}(1,25)=7.36, M S_{\mathrm{e}}=$ $4,324.13, p=.012, \eta_{\mathrm{p}}^{2}=.23$ ], replicating the iconicity effect found by Zwaan and Yaxley (2003).

A multiple regression analysis was next performed on the RTs, with the dummy-coded iconicity variable and the word order frequency variable as predictors. Because the participants' RTs should not be treated as independent observations but, instead, should be considered at the person level, two regression approaches were used: a single re- 
gression method and a separate regression method (Lorch \& Myers, 1990; Richter, 2006).

In the first analyses, each participant was dummycoded, and all 32 participants were entered in the regression model in a stepwise fashion $[F(31,872)=9.518$, $\left.p<.001, r^{2}=.26\right]$. Residuals of this regression analysis were saved and used as the dependent variable for a regression method with the dummy-coded iconicity and word order variables as predictors. Because of the low $r^{2}$ between iconicity and word order $\left(r^{2}=.09, p<.01\right)$, both dummy-coded variables were entered simultaneously in the regression model in a stepwise fashion. This resulted in a small effect size with an $R^{2}$ of .014 , with significant beta weights being obtained for word order $[\beta=-.096$; $t(841)=-2.809, p=.005]$ and iconicity $[\beta=-.07$; $t(841)=-2.029, p=.043]$.

In the second analysis, separate regression models were created per participant, using iconicity and word order as the predictors on RTs. Paired-sample $t$ tests were next performed on the $\beta$ weights for iconicity and word order obtained from the participant analyses in order to determine whether the patterns for iconicity and word order were statistically different. $\beta$ weights for iconicity were slightly lower than those for word order $(M=-.06, S D=.18$ vs. $M=-.09, S D=$ .17 , respectively). A paired-sample $t$ test showed that the word order frequency $\beta$ weights significantly differed from zero $[t(31)=-2.98, p<.01]$ but that iconicity approached significance $[t(31)=-2.026, p=.051]$. Both regression models showed that RT was better explained by word order than by iconicity.

In addition, a regression analysis was run using the participant ratings discussed in Experiment 1 and frequency of word pairs as the independent variables and RT as the dependent variable. A regression on the residuals of the RTs when individual differences were filtered out had an effect size of $R^{2}=.02$. However, the effect could be attributed only to the frequency variable $(\beta=-.14 ; t=$ $-2.91, p<.005)$, and not to iconicity $(\beta=-.03 ; t=$ $-0.53, p=.6)$. A separate regression method in which $\beta$ values were compared with zero yielded significant differences for both frequencies and participant ratings $[t(31)=-4.05, p<.001$, and $t(31)=-2.69, p=.01$, respectively; $M=-.16, S D=.23$, and $M=-.12, S D=$ .25 , respectively].
These results show that frequency of word order explains the RT at least as well as iconicity. This begs the question of whether iconicity is the prevalent factor in processing, which also happens to be encoded in language patterns, or language patterns are the prevalent factor in processing, which sometimes can be embodied. There are two ways to answer this question. One is by looking at those items for which the symbolic account and the embodied account make opposite predictions; the second is by looking at word pairs that do not have an iconicity relation. Both answers will be explored next.

The first critical test between the symbolic and the embodied accounts lies in those word pairs for which the frequency pattern did not match the iconicity pattern. Eight of the items in Table 1 were included in Experiment 1. Higher RTs for the reverse-iconic pattern than for the iconic pattern would provide evidence for the iconic account, whereas an opposite pattern would provide evidence for a symbolic account. ANOVAs on the RTs for these items showed no difference between iconic and reverse-iconic $\left[F_{1}(1,31)=\right.$ $0.039, M S_{\mathrm{e}}=19,601.49, p=.85, \eta_{\mathrm{p}}^{2}=.001 ; F_{2}(1,7)=$ $\left.0.01, M S_{\mathrm{e}}=5,003.72, p=.94, \eta_{\mathrm{p}}^{2}=.001\right]$, although iconicity items had slightly higher RTs than did reverse-iconic items $(M=1,255.49, S D=224.96$, and $M=1,262.38$, $S D=243.65$, respectively) (see Table 2). These results show that for those word pairs for which a symbolic account makes a prediction opposite the prediction made by the embodied account, the iconicity effect disappears in RTs.

Benor and Levy's (2006) word pairs did not have an obvious spatial iconicity relation. Their data set was therefore ideal for testing whether word order for word pairs without a spatial iconicity relation also affected language processing. As in the previous analysis, word order frequency from the three- to five-word window span in the Web $1 T 5$-gram corpus was computed. These frequencies were again used in two regression approaches: a single regression method and a separate regression method. In the first regression analysis, the residuals of the participant analysis were used as dependent variables and the word order as predictor. Word order significantly predicted RT $\left[R^{2}=.02, \beta=-.13 ; t(1810)=-7.13, p<.001\right]$.

In the second analysis, a paired-sample $t$ test was conducted on the $\beta$ weights in a by-participant regression analysis. A paired-sample $t$ test showed that word order

Table 2

Eight Word Pairs Included in Experiment 1, With Opposite Predictions in the Statistical Versus Embodied Account

\begin{tabular}{|c|c|c|c|c|c|c|c|c|c|}
\hline \multirow[b]{2}{*}{ Word1 } & \multirow[b]{2}{*}{ Word2 } & \multicolumn{2}{|c|}{$\begin{array}{l}\text { RT Iconic } \\
\text { Presentation }\end{array}$} & \multicolumn{2}{|c|}{$\begin{array}{c}\text { RT Reverse-Iconic } \\
\text { Presentation } \\
\end{array}$} & \multirow{2}{*}{$\begin{array}{c}\text { Frequency } \\
\text { [Word1 - Word2] }\end{array}$} & \multirow{2}{*}{$\begin{array}{c}\text { Frequency } \\
\text { [Word2 - Word1] }\end{array}$} & \multicolumn{2}{|c|}{$\begin{array}{c}\text { Participant } \\
\text { Iconicity } \\
\text { Ratings } \\
\end{array}$} \\
\hline & & $M$ & $S D$ & $M$ & $S D$ & & & $M$ & $S D$ \\
\hline branch & root & $1,395.67$ & 417.92 & $1,255.56$ & 362.72 & 3,209 & 25,701 & 4.57 & 1.37 \\
\hline ceiling & floor & $1,181.73$ & 386.91 & $1,234.87$ & 290.79 & 46,118 & 169,711 & 5.57 & 0.69 \\
\hline curtain & stage & $1,421.73$ & 361.39 & $1,310.27$ & 321.04 & 1,172 & 1,698 & 4.36 & 1.22 \\
\hline fender & tire & $1,324.60$ & 305.25 & $1,349.00$ & 379.96 & 271 & 590 & 3.93 & 1.80 \\
\hline flower & stem & 983.41 & 261.38 & $1,053.44$ & 327.75 & 3,872 & 5,099 & 5.18 & 1.19 \\
\hline headlight & bumper & $1,246.93$ & 401.73 & $1,312.33$ & 294.03 & 128 & 219 & 4.11 & 1.57 \\
\hline lid & cup & $1,194.31$ & 279.12 & $1,315.47$ & 510.64 & 1,852 & 5,789 & 4.71 & 1.24 \\
\hline sweater & pants & $1,289.38$ & 365.67 & $1,185.56$ & 329.94 & 2,156 & 2,529 & 4.61 & 1.26 \\
\hline
\end{tabular}


significantly differed from zero $[t(31)=-6.61, p<.001$; mean $\beta=-.15, S D=.12]$.

These results of Experiment 1 show that spatial iconicity affects RT in a semantic judgment task, as was argued in Zwaan and Yaxley (2003). Contrary to Zwaan and Yaxley, the findings can best be explained by language patterns, rather than by perceptual simulation.

\section{EXPERIMENT 2}

Zwaan and Yaxley (2003) showed that their iconicity effects were obtained only for vertically presented word pairs. When they presented word pairs horizontally, no iconicity effect was obtained, supporting their iconicity hypothesis. This is a problem for a lexical statistics explanation of the data. With words typically being presented horizontally rather than vertically, the question is whether word order also has an effect in the horizontal spatial arrangement, which language users are more familiar with.

\section{Method}

Participants. Seventeen undergraduate students from the University of Memphis participated in this experiment for psychology course credit. None of them had participated in the previous experiment.

Design and Materials. Twenty-eight word pairs from Zwaan and Yaxley (2003) were selected by taking those pairs with the highest and 30 pairs with the lowest semantic associations, as determined by LSA (Landauer \& Dumais, 1997; see Appendix A).

Procedure. The procedure was identical to that in Experiment 1.

\section{Results and Discussion}

Outliers were removed using the same criteria as those in Experiment 1. This affected $1.8 \%$ of the data. As in Zwaan and Yaxley (2003), no significant differences were found for iconicity $\left[F_{1}(1,16)=2.27, M S_{\mathrm{e}}=5,974.54\right.$, $p=.16, \eta_{\mathrm{p}}^{2}=.12 ; F_{2}(1,27)=0.15, M S_{\mathrm{e}}=29,974.92$, $p=.7, \eta_{\mathrm{p}}^{2}=.01$; iconic pairs, $M=1,139.4, S D=305.9$; reverse-iconic pairs, $M=1,099.83, S D=311.15]$.

As in the analyses in Experiment 1, regression analysis tested the effect of iconicity and word order on RTs. In the first regression model, each participant was dummycoded and all 17 participants were entered in the regression model in a stepwise fashion $[F(16,437)=23.56, p<$ $\left..001, r^{2}=.46\right]$. Residuals of this regression analysis were saved and used as the dependent variable for a regression method, with iconicity and word order frequencies as predictors. The $R^{2}$ for both variables was . 02 , with significant $\beta$ weights obtained for word order $[\beta=-.12 ; t(373)=$ $-2.39, p=.02]$ but not for iconicity $[\beta=.06 ; t(373)=$ $1.13, p=.26]$.

In the second analysis, separate regression models were created per participant, using iconicity and word order frequencies as the predictors on RTs. Paired-sample $t$ tests were next performed on the $\beta$ weights for iconicity and frequencies obtained from the participant. A pairedsample $t$ test showed that $\beta$ weights for word order again significantly differed from zero $[t(16)=-3.36, p<.01$; $M=-1.18, S D=.23]$ but those for iconicity did not $[t(16)=1.97, p=.07 ; M=.08, S D=.17]$.
A regression analysis using participant ratings showed a significant effect neither in the single regression method using the residuals nor in the separate regression method using the $\beta$ values per participant $[\beta=-.11 ; t(156)=$ $-1.09, p=.28$, and $t(16)=1.02, p=.32 ; M=-.11$, $S D=.46$, respectively]

As in the vertical spatial arrangement experiment, word order explained a significant part of the variance, but iconicity did not.

\section{GENERAL DISCUSSION}

Comprehenders process iconic word pairs of the type attic-basement more quickly than they do basement-attic when the word pairs are presented to them in a vertical spatial arrangement. This effect disappears in a horizontal spatial arrangement. An embodied account suggests that comprehenders perceptually simulate these word pairs and, because attics tend to be higher and basements lower, iconic pairs are processed more quickly than reverseiconic pairs.

A complementary explanation proposed by a symbolic account is that attic-basement is processed more quickly than basement-attic because attic more frequently precedes basement in everyday language use. This explanation is a complementary one to Zwaan and Yaxley's (2003) hypothesis: Prelinguistic conceptualizations (spatial iconicity) shape linguistic conceptualizations (word order), with higher concepts preceding lower concepts, as was suggested by Cooper and Ross (1975), Givón (1989), and Greenberg (1963). The results presented in this article support a symbolic account: (1) Iconic word pairs are more frequent than reverse-iconic word pairs; (2) word order frequency correlates with participants' iconicity ratings; (3) word order frequency explains RTs in a semantic judgment task better than iconicity does; (4) for those word pairs for which the symbolic account and the embodiment account make opposite predictions, no iconicity differences in RTs are found; (5) frequency of word pairs that do not have an iconic relation still explains RTs in a semantic judgment task; and (6) when iconic word pairs are presented in a horizontal arrangement, the iconicity effect disappears, but the word order effect remains.

In considering word order, we ignored syntax and looked only at the order of word pairs in a three- to fiveword window span, regardless of the words in between the target words. By considering the various discourse constraints, noise in the data could be reduced. However, even without these constraints, corpus linguistic patterns are very much in the line of Zwaan and Yaxley (2003) and follow the patterns proposed by Cooper and Ross (1975). Moreover, frequency of these word patterns significantly explains RTs in semantic judgment tasks.

The findings here suggest that linguistic conceptualizations (word order) reflect prelinguistic conceptualizations (iconicity). Where these language patterns come from is a question that falls outside the scope of this article, although theoretical answers have been proposed (Givón, 1989; Greenberg, 1963; Seidenberg, MacDonald, \& Saffran, 2002). 
In a nutshell, the results presented in this article at least support the idea that experimental findings attributed to an embodiment account can also be explained by a symbolic account. What an embodiment account typically shows is a recognition of the importance of embodied cognition. The results presented here show that language encodes these embodied relations and that these encodings explain experimental data better than embodied relations do. However, the argument here is not that embodied explanations should be discarded. Instead, the argument is that language patterns are built onto embodied relations, thereby providing comprehenders with a useful symbolic shortcut to embodied meaning. Findings from the embodied cognition literature that appear to support perceptual simulation during real-time language comprehension may actually be due to statistical relationships between words that were built from those embodied experiences.

\section{AUTHOR NOTE}

This research was supported by Grant NSF-IIS-0416128. The usual exculpations apply. I thank Rick Dale, David Rapp, and Rolf Zwaan for comments on previous drafts. Correspondence concerning this article should be addressed to M. M. Louwerse, Department of Psychology, Institute for Intelligent Systems, University of Memphis, Psychology Building, Memphis, TN 38152 (e-mail: mlouwerse@memphis.edu).

\section{REFERENCES}

BenOR, S. B., \& LeVy, R. (2006). The chicken or the egg? A probabilistic analysis of English binomials. Language, 82, 233-278.

Bergen, B. K., Lindsay, S., Matlock, T., \& Narayanan, S. (2007). Spatial and linguistic aspects of visual imagery in sentence comprehension. Cognitive Science, 31, 733-764.

Brants, T., \& Franz, A. (2006). Web $1 T$ 5-gram Version 1. Philadelphia: Linguistic Data Consortium.

Cooper, W. E., \& Ross, J. R. (1975). World order. In R. E. Grossman, L. J. San, \& T. J. Vance (Eds.), Papers from the parasession on functionalism (pp. 63-111). Chicago: Chicago Linguistic Society.

Givón, T. (1989). Mind, code and context: Essays in pragmatics. Hillsdale, NJ: Erlbaum.

GREENBERG, J. H. (1963). Some universals of grammar with particular reference to the order of meaningful elements. In J. H. Greenberg (Ed.), Universals of grammar (pp. 73-113). Cambridge, MA: MIT Press.
Kaden, S. E., Wapner, S., \& Werner, H. (1955). Studies in physiognomic perception: II. Effect of directional dynamics of pictured objects and of words on the position of the apparent horizon. Journal of Psychology: Interdisciplinary \& Applied, 39, 61-70.

Landauer, T. K., \& DumaIs, S. T. (1997). A solution to Plato's problem: The latent semantic analysis theory of acquisition, induction, and representation of knowledge. Psychological Review, 104, 211-240.

Landauer, T. K., McNamara, D. S., Dennis, S., \& Kintsch, W. (EDS.) (2007). Handbook of latent semantic analysis. Mahwah, NJ: Erlbaum.

LeVelt, W. J. M. (1989). Speaking: From intention to articulation. Cambridge: MA: MIT Press.

LORCH, R. F., JR., \& MYeRs, J. L. (1990). Regression analyses of repeated measures data in cognitive research: A comparison of three different methods. Journal of Experimental Psychology: Learning, Memory, \& Cognition, 16, 149-157.

LOUWERSE, M. M. (2007). Iconicity in amodal symbolic representations. In T. K. Landauer, D. S. McNamara, S. Dennis, \& W. Kintsch (Eds.), Handbook of latent semantic analysis (pp. 107-120). Mahwah, NJ: Erlbaum.

Louwerse, M. M., Cai, Z., Hu, X., Ventura, M., \& Jeuniaux, P. (2006). Cognitively inspired natural-language based knowledge representations: Further explorations of latent semantic analysis. International Journal of Artificial Intelligence Tools, 15, 1021-1040.

LouWerse, M. M., \& JeuniauX, P. (2008). Language comprehension is both embodied and symbolic. In M. de Vega, A. Glenberg, \& A. C. Graesser (Eds.), Symbols and embodiment: Debates on meaning and cognition (pp. 309-326). Oxford: Oxford University Press.

Nunnally, J. C., \& Bernstein, I. H. (1994). Psychometric theory. New York: McGraw-Hill.

Pecher, D., \& ZwaAn, R. A. (Eds.) (2005). Grounding cognition: The role of perception and action in memory, language, and thinking. Cambridge: Cambridge University Press.

RichtER, T. (2006). What is wrong with ANOVA and multiple regression? Analyzing sentence reading times with hierarchical linear models. Discourse Processes, 41, 221-250.

Seidenberg, M. S., MacDonald, M. C., \& Saffran, J. R. (2002). Does grammar start where statistics stop? Science, 298, 553-554.

ŠEtić, M., \& Domijan, D. (2007). The influence of vertical spatial orientation on property verification. Language \& Cognitive Processes, 22, 297-312.

SpIVEy, M. J., \& GenG, J. J. (2001). Oculomotor mechanisms activated by imagery and memory: Eye movements to absent objects. Psychological Research, 65, 235-241.

ZWAan, R. A., \& YAXLEY, R. H. (2003). Spatial iconicity affects semantic relatedness judgments. Psychonomic Bulletin \& Review, 10, 954-958. 
APPENDIX A

Zwaan and Yaxley (2003) Materials Used in Study 1

\begin{tabular}{|c|c|c|c|}
\hline airplane-runway ${ }^{* \dagger}$ & eyes-whiskers & jam-toast ${ }^{\dagger}$ & pitcher-mound ${ }^{\dagger}$ \\
\hline antenna-radio $^{\dagger}$ & faucet-drain & jockey-horse & plant-pot \\
\hline antler-deer & fender-tire* & kite-string & rocket-launchpad $\dagger$ \\
\hline attic-basement ${ }^{*}$ & flame-candle ${ }^{* \dagger}$ & knee-ankle ${ }^{* \dagger}$ & roof-house \\
\hline belt-shoe* & flower-stem* & lamp-table* & roof-porch* \\
\hline billboard-highway $^{\dagger}$ & foam-beer ${ }^{\dagger}$ & lid-box ${ }^{\dagger}$ & runner-track ${ }^{\dagger}$ \\
\hline boat-lake* & fountain-pool & lid-cup* & saddle-stirrup* \\
\hline boat-trailer ${ }^{\dagger}$ & froth-coffee ${ }^{\dagger}$ & lighthouse-beach & seat-pedal \\
\hline boot-heel & glass-coaster ${ }^{\dagger}$ & mailbox-post & sheet-mattress ${ }^{*} \dagger$ \\
\hline bouquet-vase & grill-charcoal & mane-hoof & sky-ground* \\
\hline branch-root ${ }^{*}$ & handle-bucket & mantle-fireplace $^{\dagger}$ & smoke-chimney \\
\hline bridge-river* & handrail-porch ${ }^{\dagger}$ & mast-deck ${ }^{\dagger}$ & sprinkler-lawn \\
\hline car-road* & hat-scarf* & monitor-keyboard & steeple-church \\
\hline castle-moat ${ }^{* \dagger}$ & head-foot ${ }^{*}$ & mustache-beard ${ }^{\dagger}$ & stoplight-street ${ }^{\dagger}$ \\
\hline ceiling-floor ${ }^{* \dagger}$ & headlight-bumper* & nose-mouth ${ }^{*}$ & sweater-pants $* \dagger$ \\
\hline cork-bottle & hiker-trail ${ }^{\dagger}$ & pan-stove & tractor-field \\
\hline cup-saucer & hood-engine* & pedestrian-sidewalk & train-railroad ${ }^{\dagger}$ \\
\hline tum-stage & & & \\
\hline
\end{tabular}

*Stimuli used in Experiment 1. †Stimuli used in Experiment 2.

\section{APPENDIX B}

Selected Benor and Levy (2006) Materials Used in Experiment 1

\begin{tabular}{|c|c|c|c|}
\hline questions-answers & night-day & principal-interest & dessert-champagne \\
\hline fitness-exercise & puddings-pies & recognition-pride & pie-bar \\
\hline sisters-brothers & tail-head & weekends-nights & students-parents \\
\hline silver-gold & trees-deer & satire-irony & movie-book \\
\hline third-second & kings-commoners & science-math & trade-finance \\
\hline winter-summer & humans-animals & friends-family & food-drinks \\
\hline television-radio & humor-comedy & drawers-closets & sports-crime \\
\hline cans-bottles & sit-ups-push-ups & wink-laugh & soils-people \\
\hline roses-flowers & years-months & dinner-dancing & snobbery-romance \\
\hline women-men & egg-chicken & meaning-emotion & postmasters-clerks \\
\hline nuts-fruit & takeoffs-landings & salt-pepper & sandalwood-ivory \\
\hline son-daughter & suits-dresses & milk-honey & toe-fronts \\
\hline snow-ice & sweaters-skirts & odds-ends & yeast-medicines \\
\hline lawn-garden & radio-newspaper & tuition-rent & smoke-mirrors \\
\hline anxiety-anger & rape-incest & mother-dad & peacocks-hell \\
\hline
\end{tabular}

(Manuscript received May 28, 2007;

revision accepted for publication January 29, 2008.) 